\title{
REFORMASI PELAYANAN PUBLIK DI DPMPTSP
}

\author{
Novliza Eka Patrisia ${ }^{1}$, Faizal Anwar ${ }^{2}$ \\ Universitas Muhammadiyah Bengkulu ${ }^{1,2}$ \\ novlizaekap@umb.ac.id ${ }^{1}$
}

\begin{abstract}
ABSTRAK
Penelitian ini bertujuan untuk mengetahui pelaksanaan dan aspek-aspek yang menghambat reformasi pelayanan publik di DPMPTSP Kota Bengkulu dalam mencapai pelayanan prima. Metode yang digunakan dalam penelitian adalah metode kualitatif dengan analisis deskriptif. Hasil penelitian menunjukkan bahwa pelayanan di DPMPTSP sudah mencakup 10 aspek pelayanan publik seperti kesederhanaan, kejelasan, kepastian, keamanan, tanggung jawab, kelengkapan sarana dan prasarana, kemudahan akses, kedisiplinan, dan kenyamanan. Sedangkan aspek penghambat seperti penyelesaian waktu perizinan yang lama, perawatan sarana dan prasarana, kurangnya lahan parkir, belum semua masyarakat memanfaatkan portal website. Simpulan penelitian ini bahwa pelaksanaan reformasi pelayanan di DPMPTSP sudah menunjukkan pelayanan yang prima dan aspek yang perlu ditingkatkan seperti memaksimalkan penggunaan teknologi, kedisiplinan, dan kelengkapan sarana dan prasarana.
\end{abstract}

Kata Kunci: Pelayanan Publik, Reformasi Administrasi, Tata Kelola.

\section{ABSTRACT}

This study aims to determine the implementation and aspects that hinder public service reform in Bengkulu City DPMPTSP in achieving excellent service. The method used in this research is a qualitative method with descriptive analysis. The results of the study indicate that services at DPMPTSP already cover 10 aspects of public services such as simplicity, clarity, certainty, security, responsibility, completeness of facilities and infrastructure, ease of access, discipline, and comfort. While the inhibiting aspects such as the completion of long licensing times, maintenance of facilities and infrastructure, lack of parking space, not all people use the website portal. The conclusion of this study is that the implementation of service reform in DPMPTSP has shown excellent service and aspects that need to be improved such as maximizing the use of technology, discipline, and completeness of facilities and infrastructure.

Keywords: Administrative Reform, Governance, Public service. 


\section{PENDAHULUAN}

Rata-rata orang mafhum, harga diri pemerintahan diukur dari kualitas pelayanan. Cobalah gunakan kacamata yang lebih sederhana. Jadikan masyarakat awam sebagai rujukan untuk melihat masalah-masalah pelayanan di lapangan. Kenapa? Masyarakat kebanyakan sudah akrab dengan masalah-masalah pelayanan keseharian, mulai dari pengurusan KTP hingga perbaikan jalan rusak; mulai dari pemilihan kepala daerah hingga stabilisasi pertumbuhan ekonomi nasional. Merekalah yang paling mengalami dampak kualitas pelayanan.

Pelayanan publik di Indonesia sendiri saat ini dapat dikatakan masih jauh dari harapan. Fenomena birokrasi yang berbelit-belit dan korupsi masih terjadi pada banyak pelayanan yang diselenggarakan birokrasi pemerintah. Pada 2011 saja Ombudsman RI mencatat 5.800 masalah yang kerja di dalam pelayanan dari seluruh wilayah Indonesia, itu pun baru yang dilaporkan, belum masalah pelayanan yang belum dilaporkan. Pelayanan Pemda dianggap terburuk, diikuti kepolisian, lembaga peradilan, Badan Pertanahan Nasional, bahkan BUMN/D ikut terseret. (Pasolong, 2007)

Reformasi birokrasi adalah reformasi pelayanan publik itu sendiri. Apakah reformasi pelayanan publik belum dilakukan? Sebenarnya perlu diakui bahwa upaya perbaikan pelayanan publik sudah dilakukan. Standardisasi pelayanan minimal sudah diberlakukan untuk pelayanan dasar; UU No. 25 Tahun 2009 memapankan pengaturannya. Modernisasi pelayanan dengan instrumentasi teknologi informasi juga bukan hal baru lagi. Pada perkembangannya, pelayanan publik ada yang secara langsung dikelola oleh negara, ada pula yang diserahkan kepada swasta dalam pemenuhannya.

Terlalu naif untuk mencukupkan upaya perbaikan dengan cara-cara di atas. Masyarakat sebagai pemangku utama dan referensi dalam evaluasi kinerja pelayanan publik justru masih belum banyak dilibatkan dalam perbaikan pelayanan publik. Alasan di balik kekurangan ini beragam, mulai dari keengganan lembaga pemerintah itu sendiri hingga anggapan ketidakmampuan masyarakat.

Jika sudah ada standar pelayanan minimal (SPM), untuk apa lagi kemudian ada pengembangan standar pelayanan? Standar pelayanan seharusnya menyesuaikan dengan kecenderungan dan kesanggupan masyarakat secara riil. SPM berkenaan dengan pelayanan dasar, seperti pendidikan dan kesehatan. Namun, mengoptimalkan pelayanan tidak cukup dengan SPM tapi harus lebih mengena pada kebutuhan yang lebih luas di lapangan. Sebagai pelaksanaan dari pasal-pasal terkait dengan standar pelayanan pada UU No. 25 tahun 2009, Pemerintah juga telah memberlakukan PermenPan-RB nomor 36 tahun 2012 tentang Petunjuk Teknis Penyusunan, Penetapan, dan Penerapan Standar Pelayanan. Peraturan memuat sejumlah panduan bagi penyelenggara pelayanan dalam menyusun standar pelayanan. Tujuannya agar penyelenggara pelayanan mampu untuk memberikan kepastian, meningkatkan kualitas dan kinerja pelayanan sesuai dengan kebutuhan masyarakat.

Masyarakat juga perlu dilibatkan secara konkret dalam standardisasi pelayanan publik. Pembuatan standar pelayanan atas dasar kesepakatan dengan masyarakat 
merupakan langkah yang tepat untuk mengeluarkan komitmen penyelenggara atau yang dikenal sebagai maklumat standar pelayanan (citizen charter).

Wujud nyata dari penerapan reformasi birokrasi di Indonesia adalah pengembangan pelayanan perizinan terpadu. Penyelenggaraan pelayanan perizinan terpadu diawali dari disahkannya Peraturan Menteri Dalam Negeri Nomor 24 Tahun 2006 tentang Pedoman Penyelenggaraan Pelayanan Terpadu Satu Pintu. Bentuk implementasi Reformasi di Kota Bengkulu adalah terbentuknya DPMPTSP. DPMPTSP Kota Bengkulu mempunyai kewenangan untuk melakukan pelayanan perizinan berupa pelayanan satu pintu yang diharapkan dapat merampingkan birokrasi dan memberikan pelayanan prima kepada masyarakat dengan memberikan kemudahan dalam pengurusan berbagai izin dengan cukup mendatangi satu tempat saja.

Permasalahan yang berkaitan dengan Reformasi Birokrasi memunculkan area perubahan Reformasi Birokrasi dikelompokkan menjadi 8 area yaitu: 1) Organisasi; 2) Tatalaksana; 3) Peraturan Perundangundangan; 4) Sumber daya manusia aparatur; 5) Pengawasan; 6) Akuntabilitas; 7) Pelayanan Publik serta; 8) Pola pikir (mindset) dan Budaya Kerja (culture set) Aparatur publik.

Dilihat dari kedelapan area perubahan Reformasi Birokrasi peneliti tertarik untuk meneliti perubahan Reformasi Birokrasi terutama di area Pelayanan Publik yang bertujuan untuk memberikan pelayanan prima kepada masyarakat sesuai dengan kebutuhan dan harapan dari masyarakat. Saat ini pelayanan publik yang ada belum menunjukkan pelayanan prima. (Barata, 2004)

$$
\text { Pelaksanaan }
$$

reformasi

birokrasi pelayanan publik di DPMPTSP Kota Bengkulu belum berjalan dengan baik dikarenakan masyarakat tidak mengetahui dengan benar persyaratan yang harus dipenuhi sehingga perizinan tidak dapat langsung di proses, adanya calo yang menawarkan jasanya karena dalam mengurus perizinan membutuhkan waktu yang lama, adanya biaya tambahan yang diberikan oleh pelanggan kepada oknum pegawai untuk mempercepat pengurusan izin atau sekedar ucapan terima kasih. (Komarudin, 2014)

$$
\text { Permasalahan selanjutnya }
$$

adalah Standar Operasi Prosedur (SOP) belum lengkap seperti belum terpampangnya persyaratan mengenai berbagai jenis perizinan sehingga pelanggan hanya dapat mengetahuinya melalui brosur maupun bertanya langsung kepada pegawai. Minimnya sosialisasi yang dilakukan oleh pihak DPMPTSP Kota Bengkulu menghambat dalam pengurusan perizinan karena masyarakat tidak mengetahui dengan benar jenis perizinan, syarat perizinan maupun alur perizinan. Selain itu, diperlukan surat rekomendasi izin dari Satuan Kerja Perangkat Daerah (SKPD) terkait agar izin dapat diterbitkan seperti izin Mendirikan Bangunan dan izin Reklame.

Belum maksimal pemanfaatan portal website dan sarana prasarana yang belum mendukung seperti tempat parkir yang memadai, ruang tunggu pelayanan yang digunakan oleh orang yang tidak sedang mengurus izin, dan pohon saran dan pengaduan yang tidak berfungsi dengan baik juga menyebabkan pelayanan yang diberikan belum menunjukkan pelayanan prima. 


\section{METODE PENELITIAN}

Penelitian ini menggunakan metode penelitian kualitatif dengan desain penelitian deskriptif. (Sugiono, 2009). Penelitian ini berlokasi di Kantor DPMPTSP Kota Bengkulu. Informan dalam penelitian ini adalah pegawai DPMPTSP Kota Bengkulu yang dipilih dengan teknik snowball sampling dan pengguna layanan perizinan yang dipilih dengan teknik insidental sampling. Sumber data digunakan adalah data primer data yang diperoleh dari responden melalui kuesioner dan hasil wawancara peneliti dengan informan dan data sekunder Berupa dokumentasi yang dimiliki oleh DPMPTSP Kota Bengkulu. Teknik pengumpulan data yang digunakan adalah pengamatan, wawancara dan dokumentasi. Data yang terkumpul kemudian diolah dan dianalisis menjadi data yang sistematis, teratur, terstruktur, dan mudah dipahami. Selanjutnya, menguji kualitas data dengan teknik triangulasi data dengan melakukan pengecekan data dari berbagai sumber dengan berbagai cara, dan berbagai waktu sehingga diperoleh hasil yang mudah dipahami oleh peneliti berdasarkan data yang diperoleh dari informan.

\section{HASIL DAN PEMBAHASAN Pelaksanaan Reformasi Birokrasi Pelayanan Publik}

Terdapat 10 dimensi yang digunakan untuk melihat pelaksanaan reformasi birokrasi pelayanan publik di DPMPTSP Kota Bengkulu dalam Mencapai Pelayanan Prima, yaitu:. Pertama kesederhanaan prosedur pelayanan di DPMPTSP Kota Bengkulu telah diselenggarakan dengan mudah, lancar, cepat dan tidak berbelit-belit. Pelanggan sudah memahami dengan baik mengenai prosedur pelayanan karena sudah ada papan informasi mengenai alur atau mekanisme pelayanan yang sudah terpasang di dinding ruang tunggu.

Kedua kejelasan DPMPTSP sudah memberikan kejelasan mengenai persyaratan pelayanan yang tertera pada brosur. Rincian biaya yang sudah sesuai dengan aturan yang berlaku akan tetapi ada beberapa perizinan yang memerlukan biaya dalam pengurusannya. Sedangkan untuk pejabat yang bertanggung jawab dalam memberikan pelayanan dan penyelesaian pelayanan publik sesuai dengan bidang perizinan masingmasing. (Sarundajang, 2003)

Ketiga kepastian waktu, ada beberapa perizinan yang melebihi standar pelayanan dalam penyelesaiannya. Hal ini karena ada temuan di lapangan dan perlunya rekomendasi dari dinas terkait dalam penerbitan izin. Jadi, dalam setiap perizinan yang diterbitkan tidak semuanya sesuai dengan standar pelayanan minimal. Hal ini disebabkan oleh berbagai macam faktor baik dari pelanggan maupun pemberi pelayanan. Oleh karena itu, pelanggan wajib memberikan informasi dan melengkapi berbagai macam persyaratan yang harus dipenuhi agar izin dapat segera diterbitkan. Keempat Keakuratan produk pelayanan publik yang dihasilkan oleh DPMPTSP Kota Bengkulu berupa Surat izin yang diterima oleh pelanggan harus benar, tepat dan sah. Dalam implementasinya, produk pelayanan yang diterima oleh pelanggan berupa surat izin sudah akurat. Artinya sudah benar, tepat dan sah serta tidak terjadi kesalahan. Hal ini tidak terlepas dari tugas pegawai di bidang perizinan di DPMPTSP Kota Bengkulu untuk melakukan pengecekan dalam setiap perizinan yang akan diterbitkan. 
Kelima keamanan yang dimaksud adalah keamanan dalam pemberian kepastian hukum kepada pelanggan ketika mengurus perizinan di DPMPTSP Kota Bengkulu dan keamanan dalam proses pengurusan perizinan. Keamanan dalam proses dan produk pelayanan di DPMPTSP memberikan rasa aman dan kepastian hukum. Hal ini berupa dasar hukum. pelanggan yang sudah mengurus izin di DPMPTSP merasa aman dalam melakukan pekerjaannya karena sudah memiliki surat izin dan ada kepastian hukum sehingga sudah sesuai dengan peraturan perundang-undangan.

Keenam tanggung jawab yang diberikan pegawai di DPMPTSP Kota Bengkulu berupa pemberian pelayanan perizinan kepada pelanggan sesuai dengan bidang perizinan masingmasing sehingga setiap pegawai mempunyai rasa tanggung jawab dalam memberikan pelayanan dan menerbitkan perizinan. Penyelesaian keluhan dapat langsung menyampaikan kritikan, saran maupun masukan kepada pegawai, melalui pohon sardu (media saran dan pengaduan pelayanan), dan melalui website DPMPTSP Kota Bengkulu. Berdasarkan pengamatan yang telah dilakukan oleh peneliti, pemanfaatan pohon sardu sebagai media saran dan pengaduan belum dimanfaatkan dengan baik. Oleh karena itu, pelanggan perlu diberikan pengetahuan melalui sosialisasi mengenai beragam cara untuk menyampaikan kritik dan saran. Ketujuh kelengkapan sarana dan prasarana di DPMPTSP Kota Bengkulu sudah lumayan mencukupi, akan tetapi pelanggan mengeluhkan tempat parkir yang susah. Hal ini dikarenakan lokasi DPMPTSP Kota Bengkulu yang menjadi satu dengan kantor pemerintahan lainnya sehingga belum ada pemisahan tempat parkir untuk masing-masing kantor. Tidak berfungsinya nomor antrian perlu untuk diperbaiki sehingga apabila perizinan yang harus ditangani banyak dapat tertib, dan perlu dilakukan perawatan secara berkala mengenai sarana dan prasarana penunjang pelayanan. Sedangkan untuk ruang tunggu pelanggan sudah merasa nyaman, jumlah kursi tunggu yang tersedia sudah mencukupi. Berkaitan dengan sarana dan prasarana yang menunjang pekerjaan pegawai seperti komputer, mesin cetak, jaringan internet juga sudah tersedia sehingga dapat mempercepat penyelesaian izin. Penggunaan teknologi informasi dalam perizinan akan menghemat waktu dan mempermudah pegawai dalam melaksanakan pekerjaannya.

Kedelapan kemudahan akses menuju ke DPMPTSP Kota Bengkulu cukup mudah untuk dijangkau baik menggunakan kendaraan pribadi maupun kendaraan umum. Berbeda hal nya dengan pemanfaatan teknologi telekomunikasi dan informatika belum dimanfaatkan dengan baik. Hal ini dapat dilihat dari sudah tersedianya website DPMPTSP Kota Bengkulu akan tetapi formulir pendaftaran belum bisa didownload secara online oleh pelanggan. Oleh karena itu, pihak DPMPTSP Kota Bengkulu perlu melakukan perbaikan portal website agar dapat berfungsi dengan baik sehingga di akses oleh masyarakat.

Kesembilan kedisiplinan pegawai DPMPTSP Kota Bengkulu belum menunjukkan kedisiplinan meskipun sudah menggunakan finger print, hal ini karena pegawai kadang meninggalkan kantor saat jam kerja. Pegawai belum sepenuhnya melakukan pekerjaan dengan disiplin. Akan tetapi, pegawai sudah berlaku sopan dalam memberikan pelayanan 
dan ramah kepada pelanggan dengan memberikan senyum, salam dan sapa. Kesepuluh kenyamanan lingkungan pelayanan di DPMPTSP Kota Bengkulu yang tertib, teratur, disediakan ruang tunggu yang nyaman, bersih, rapi serta tersedianya fasilitas pendukung lainnya merupakan salah satu hal yang perlu untuk diperhatikan. Hal ini dikarenakan pelanggan merasa nyaman apabila lingkungan pelayanan nyaman dan tersedia berbagai fasilitas pendukung lainnya. Berdasarkan penelitian yang telah dilakukan dapat diketahui bahwa kenyamanan untuk ruang tunggu pelayanan sudah mencukupi, selain itu juga tersedia toilet, masjid, jalur khusus bagi penyandang berkebutuhan khusus dan ruang laktasi bagi ibu menyusui.

\section{Aspek yang Menghambat dalam Pelaksanaan Reformasi Pelayanan}

Penyelesaian waktu perizinan yang lama diakibatkan oleh temuan lapangan (gambar yang tidak sesuai) saat melakukan cek lapangan sehingga waktu penyelesaian izin menjadi lebih lama. Selain itu, juga memerlukan koordinasi dengan dinas terkait untuk mengeluarkan izin. Apabila dinas terkait belum merekomendasikan penerbitan izin maka izin tersebut belum dapat di terbitkan oleh DPMPTSP Kota Bengkulu. Oleh karena itu, perlu dilakukan koordinasi yang baik antara pelanggan izin, DPMPTSP Kota Bengkulu dengan dinas terkait dalam melakukan penyelesaian izin.

Hal yang perlu mendapat perhatian adalah perawatan semua kelengkapan sarana dan prasarana yang dilakukan secara rutin sehingga apabila terjadi kerusakan seperti tidak berfungsinya mesin nomor antrian akan segera diperbaiki. Selain itu, harus disediakan lahan parkir yang memadai dan terpisah dengan dinas lain agar memudahkan masyarakat ketika parkir kendaraan.

Kemudahan akses dalam pemanfaatan teknologi telekomunikasi dan informatika belum sepenuhnya dapat dilakukan. DPMPTSP Kota Bengkulu sudah memanfaatkan portal website akan tetapi masih ada beberapa kekurangan seperti belum bisa men-download formulir pendaftaran secara online namun untuk formulir pendaftaran sudah bisa dilakukan secara online. Selain itu tidak semua masyarakat memanfaatkan portal website tersebut. Oleh karena itu, diperlukan sosialisasi bagi masyarakat khususnya pelanggan perizinan untuk memanfaatkan portal website. Melalui portal website DPMPTSP Kota Bengkulu dapat diketahui sejauh mana izin telah di proses dengan melakukan cek validasi.

Kedisiplinan pegawai menjadi salah satu aspek yang perlu mendapat. Penggunaan sistem finger print mampu meningkatkan kedisiplinan pegawai, namun pegawai hanya bersikap tepat waktu ketika jam masuk kerja dan jam pulang kerja. Akan tetapi, pegawai terkadang meninggalkan kantor saat jam kerja untuk keluar dengan alasan yang beragam.

\section{SIMPULAN}

Tujuan pelaksanaan reformasi birokrasi pelayanan perizinan di DPMPTSP Kota Bengkulu sudah menunjukkan pelayanan prima. Hal ini dapat diketahui dari:

Penyederhanaan perizinan dilakukan sehingga waktu yang dibutuhkan singkat karena semua proses perizinan dilakukan di satu tempat berbeda dengan sebelum reformasi birokrasi perizinan harus 
dilakukan di banyak instansi.

Sudah ada kejelasan mengenai persyaratan perizinan dan kepastian biaya. Hal ini dapat diketahui melalui brosur yang telah tersedia di rak brosur.

Produk pelayanan perizinan di DPMPTSP Kota Bengkulu sudah diterima dengan benar dan sah berupa surat keputusan yang dapat digunakan sesuai dengan kebutuhan, pekerjaan atau beragam kegiatan usaha.

Terdapat 4 aspek yang menghambat dalam pelaksanaan reformasi birokrasi pelayanan publik di DPMPTSP Kota Bengkulu meliputi

$\begin{array}{lcr}\text { Kepastian } & \text { waktu } & \text { yang } \\ \text { terkadang belum } & \text { sesuai } & \text { dengan } \\ \text { standar pelayanan minimal } & \text { karena } \\ \text { adanya temuan lapangan. }\end{array}$

Kelengkapan sarana dan prasarana belum mencukupi untuk menunjang proses pelayanan

Kemudahan akses sudah dapat dijangkau oleh masyarakat ketika mengurus perizinan akan tetapi pemanfaatan perkembangan teknologi belum dimanfaatkan dengan maksimal

Kedisiplinan pegawai masih kurang walaupun sudah ada penerapan presensi menggunakan finger print, hal ini belum menyadarkan pegawai dalam memberikan pelayanan kepada pelanggan karena pegawai sering izin saat jam kerja.

\section{DAFTAR PUSTAKA}

Barata, A. A. (2004). Dasar-Dasar Pelayanan Prima. Jakarta: PT. Elex Media Komputindo.
Komarudin, K. (2014). Reformasi Birokrasi dan Pelayanan Publik. Jakarta: Genesindo.

Pasolong, H. (2007). Teori Administrasi Publik. Bandung: Alfabeta.

Sarundajang, S.H. (2003). Birokrasi dalam Otonomi Daerah: Upaya Mengatasi Kegagalannya. Jakarta: Pustaka Belajar.

Sedarmayanti, P. S. (2013). Reformasi Administrasi, Reformasi Birokrasi, dan Kepemimpinan Masa Depan. Bandung: Refika Aditama.

Sinambela, L. P. (2011). Reformasi Pelayanan Publik; Teori, Kebijakan, dan Implementasi. Jakarta: Bumi Aksara.

Sugiyono, S. (2009). Metode Penelitian Kuantitatif, Kualitatif dan R\&D. Bandung: Alfabeta.

Suwitri, S. (2008). Konsep Dasar Kebijakan Publik. Semarang: Badan Penerbit Universitas Diponegoro.

Syafiie, I. K. (2006). Ilmu Administrasi Publik (Edisi Revisi). Jakarta: Asdi Mahasatya.

Nogi, S. (2005). Hessel. Tangkilisan, Manajemen Publik. Jakarta: Gramedia Widiasarana Indonesia.

Utomo, W. (2009). Administrasi Publik Baru Indonesia: Perubahan Paradigma dari Administrasi Negara ke Administrasi Publik. Yogyakarta: Pustaka Belajar. 